\title{
PARKING AREAS IN NEIGHBORHOODS IN EGYPTIAN CITIES: PROBLEMS AND SUGGESTED SOLUTIONS
}

\author{
Esam El-Din Kamal Mahrous, Ass. Prof. \\ Architectural Engineering Department, Faculty of Engineering, Assuit \\ University, Egypt
}

(Received July 19, 2006 Accepted August 20, 2006)

Most of the Arabian cities, especially Egyptian ones, suffer from the lack of parking areas in most of its parts, due to-high rates of population density. This problem is common in all parts of the city either the city center or inside the residential districts. This problem exacerbates on an annual basis due to increasing car possession, while urban areas in Egypt is limited. The aim of this paper is to find the most important reasons and aspects of parking areas' problem within the residential areas and neighborhoods. The shortage of the legal and administrative aspects, the weakness public transportation systems are considered the most important reasons behind this problem. Consequently, according to the preliminary observations stated above, the research suggests some solutions, which formulate a comprehensive plan to overcome the parking areas' problem in the residential districts and neighborhoods in Egypt.

\section{انتظار السيارات في الأحياء السكنية بالمدن المصرية: المشاكل والحلول

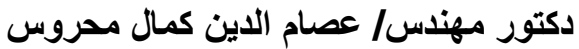 \\ أستاذ التخطيط العمر اني و الإقليمي المساعد/ قسم الهندسة المعمارية مدئ/ كلية الهندسة/جامعة أسيوط

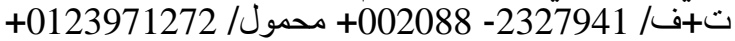 \\ essam_mahrous@yahoo.com dr_}

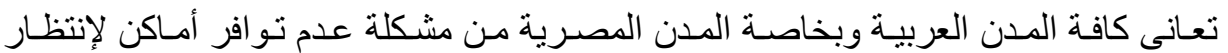

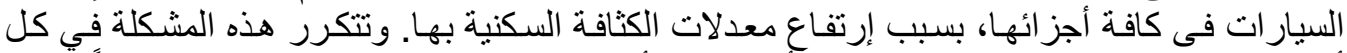

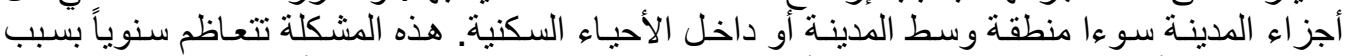

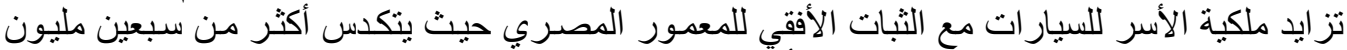

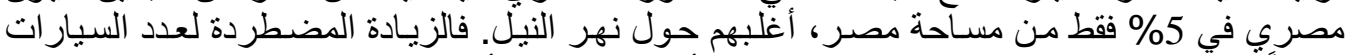

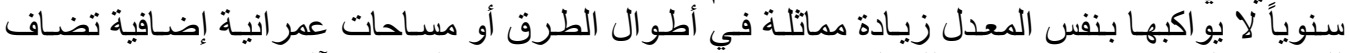

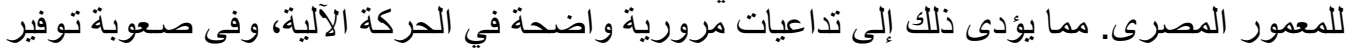

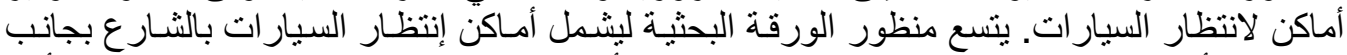

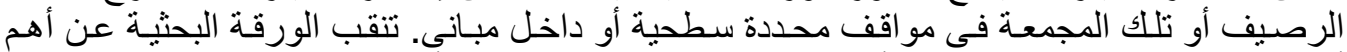
أسباب ومظاهر مشكلة عدم تو افر أمسكن لإنتظار السيار ات داخل الأحياء السكنية بالمدينة المصرية.

فترصد أن القصور في البنود والإجراءات القانونية المنظمة للعمر ان وعدم توفر أنظمة 1623 


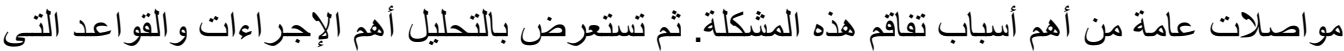

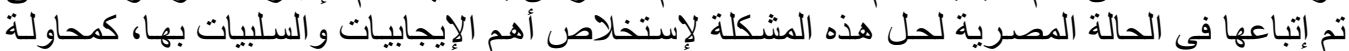

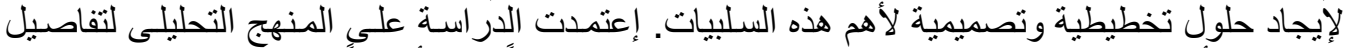

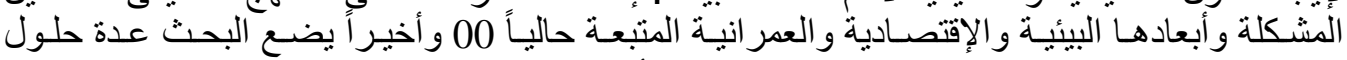
تخطيطية وتصميمية لمشكلة إنتظار السيار ات داخل الأحياء السكنية بالمدينة المصرية.

\section{1- المقدمة: مشكلة البحث وأهدافهه}

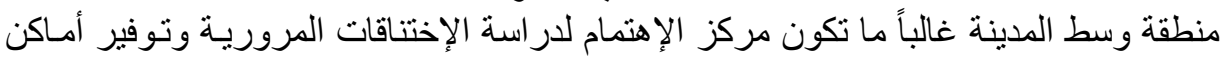

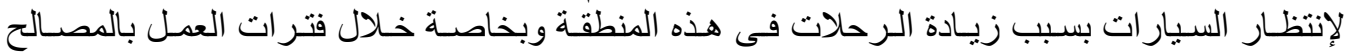

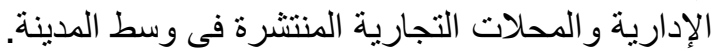

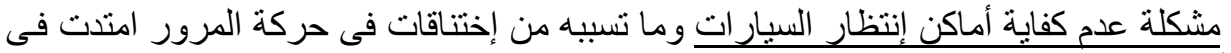

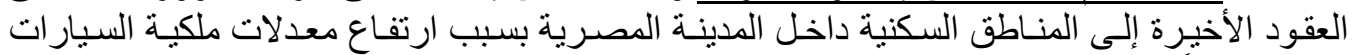

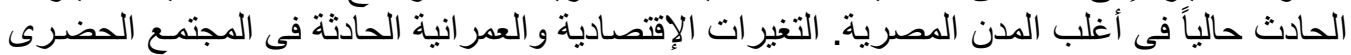

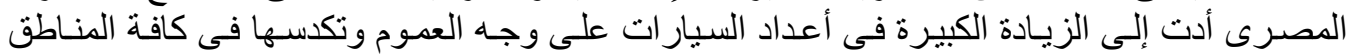

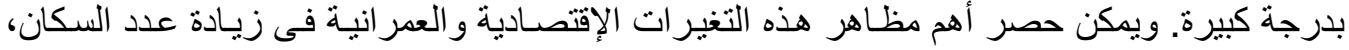

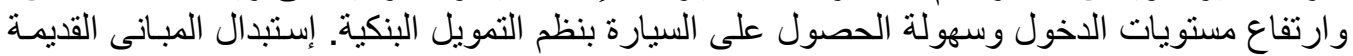

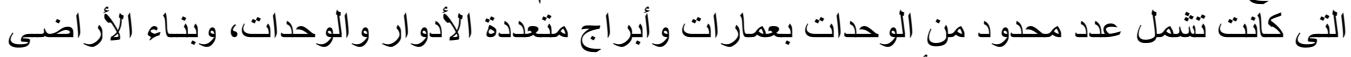

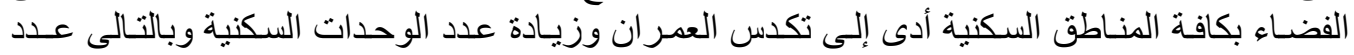

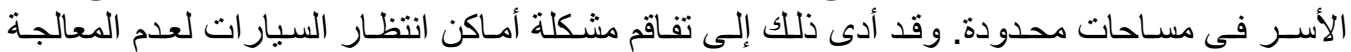

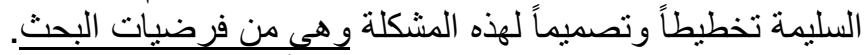

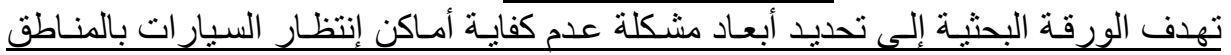

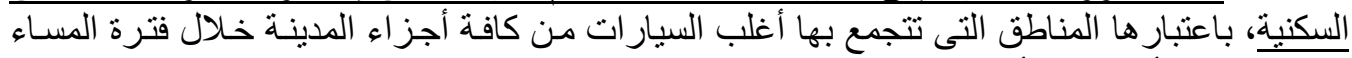

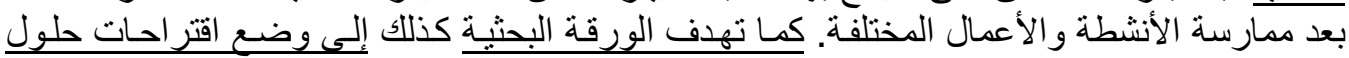

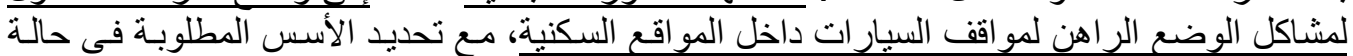

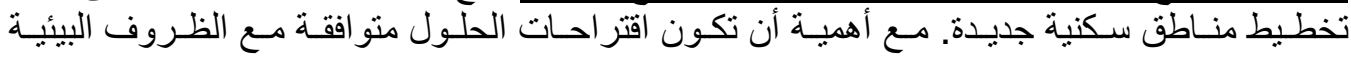
والإقتصادية والإجتماعية.

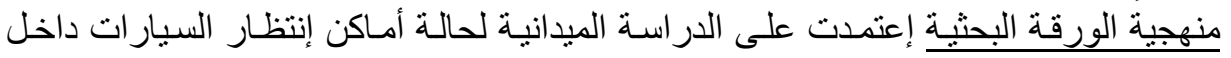

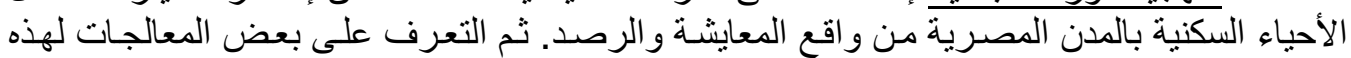

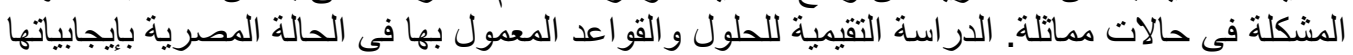

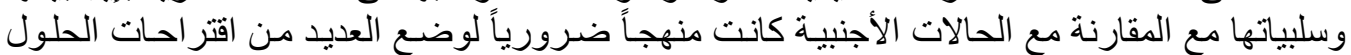

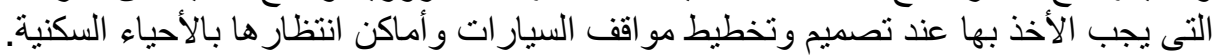

\section{2- أسباب ومظاهر مشكلة إنتظار السيارات بالمناطق السكنية}

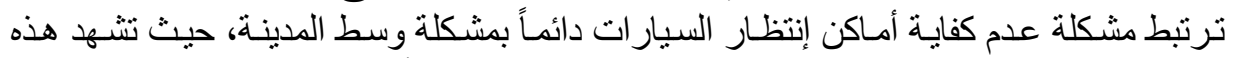

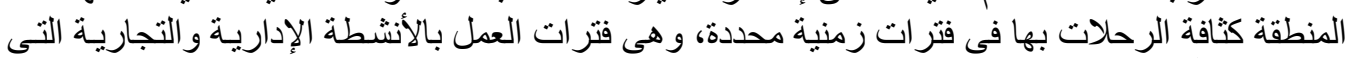

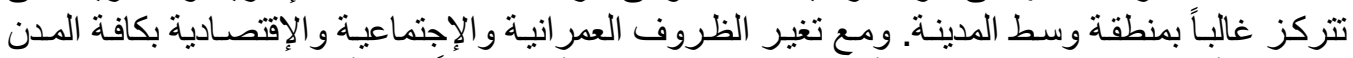

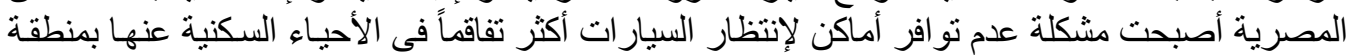

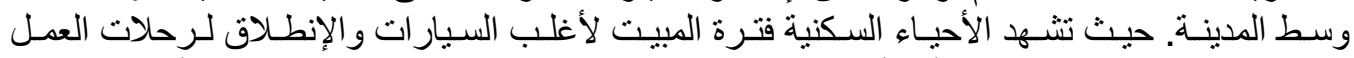

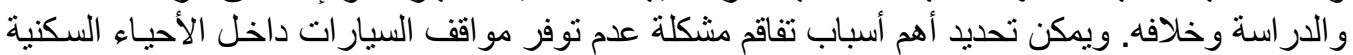
فى التالى: 1-2 - الزيادة المتصاعدة فى أعداد السكان فى كافة المدن المصرية: 


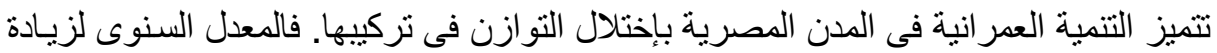

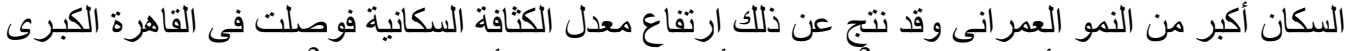

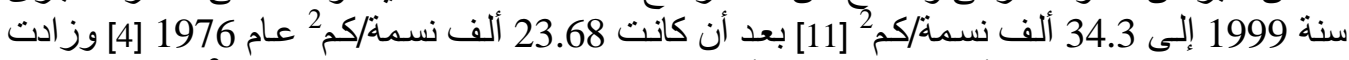

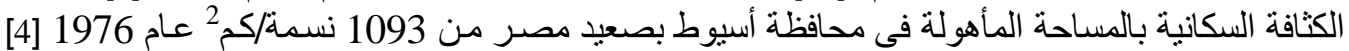

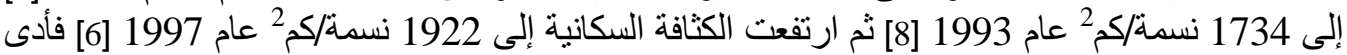
ذلك إلى زيادة الكثافة السكنية داخل الأحياء التقليدية وذلك بيناء أغلب المناطق الفضاء الفية الفئ داخل الأحياء وتعلية

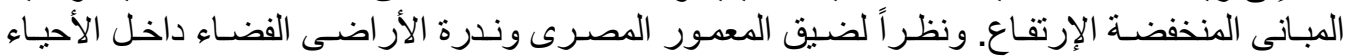

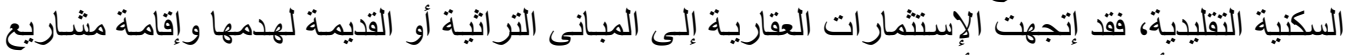

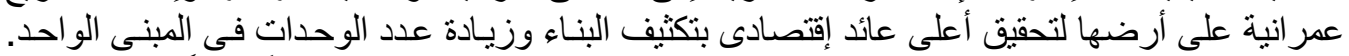

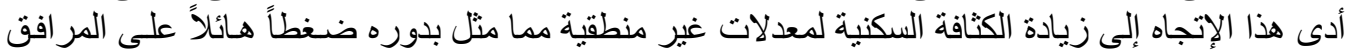

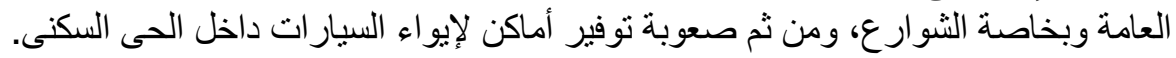

2-2 - مشاريع الإسكان غير الملتزمة بالشروط البنائية والتظيمية:

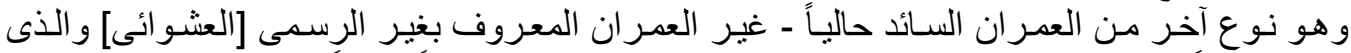

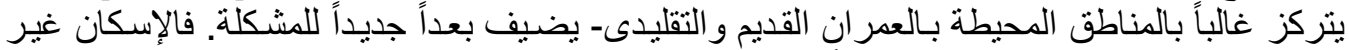

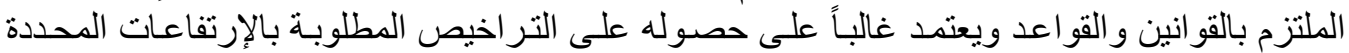

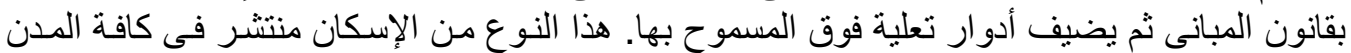

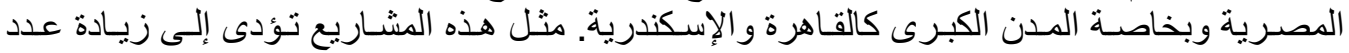

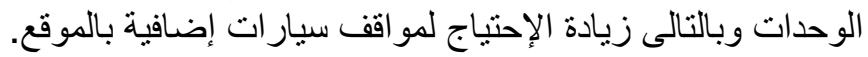

3-2 - التخطيط غير الملائم لشبكة الشوارع:

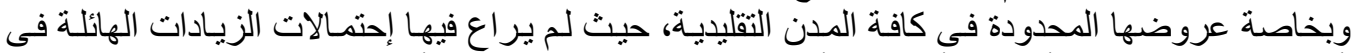

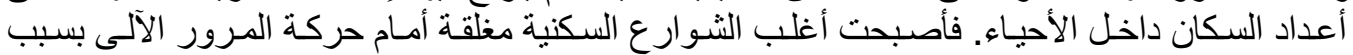

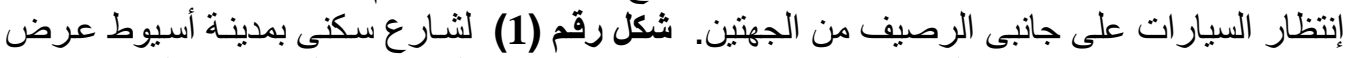

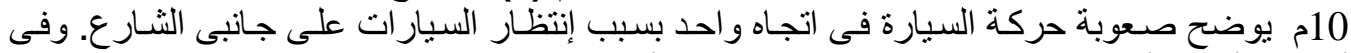

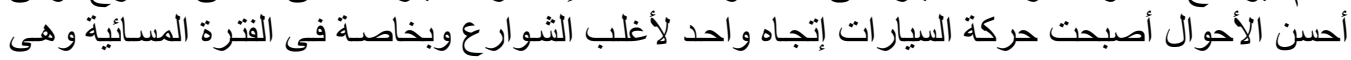
فترة مبيت السيار ات بجوار الآ المساكن.

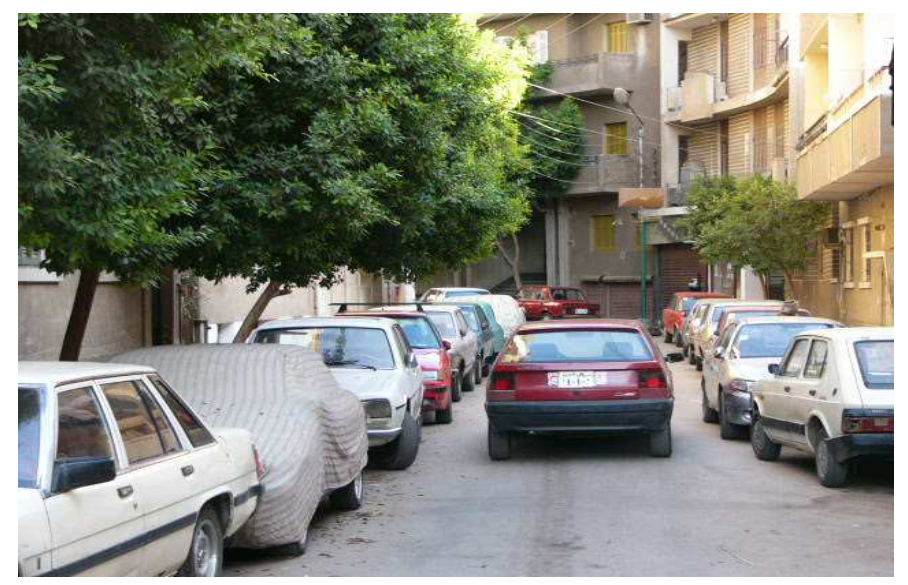

شكل رقم (1): عدم ملائمة عروض الشوارع السكنية لإنتظار السيار ات على جانبى الشارع.

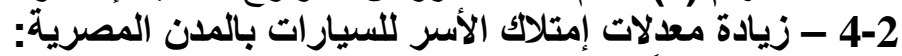

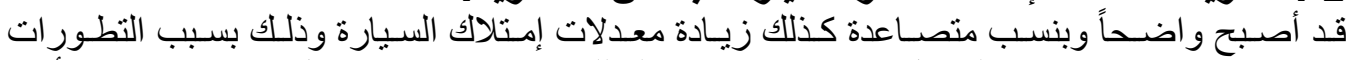

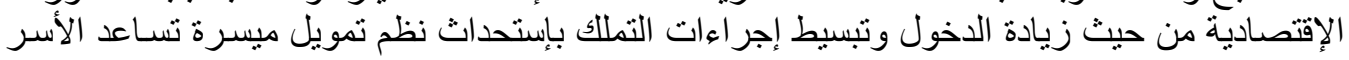


على إمتلاك سيارة أو أكثر. فبناءاً على الإحصاءات المرورية تطورت معدلات ملكية السيارة لكل ألف

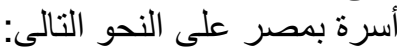

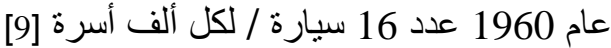

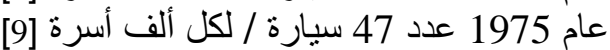

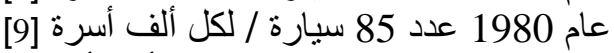

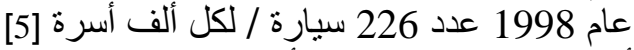

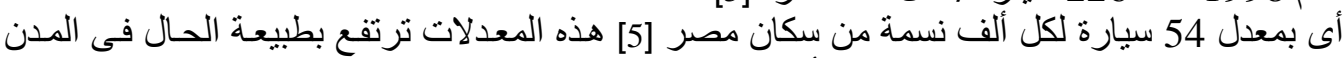

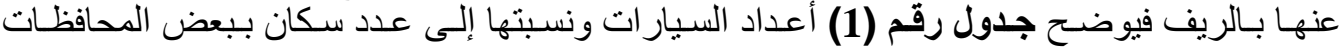
وفى بعض الأحياء السكنية الر اقية التى بقطنها غالباً الأسر ذات الدخول المرتفعة تزيد معدلات إمتلاك الأسرة الو احدة لعدة سيار اتلات.

جدول رقم (1): أعداد السيارات ونسبتها إلى عدد السكان و الأسر ببعض المحافظات الحضرية بمصر

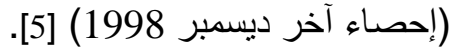

\begin{tabular}{|c|c|c|c|c|c|}
\hline الأسرة سط حجرداً) & لكل ألف أسرة & لكل عدد السيار ات 1000 فرد & 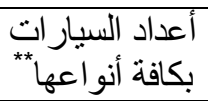 & عام 1998 عدان & المحافظة \\
\hline 4.1 & 524 & 128 & 904535 & 7089632 & القاهرة \\
\hline 4.2 & 440 & 105 & 367201 & 3480789 & الإسكندرية \\
\hline 4.1 & 360 & 88 & 43616 & 492370 & بورسعيد \\
\hline
\end{tabular}

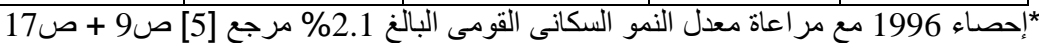

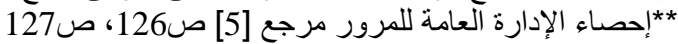

\section{5-2 - 5صور أنظمة المواصلات العامة والمرور داخل المدينة:}

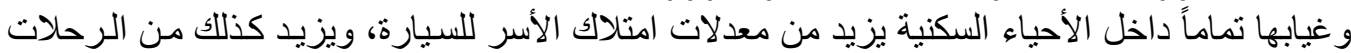

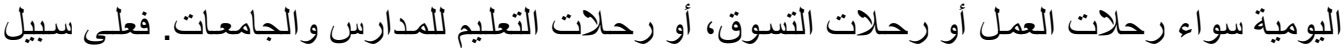

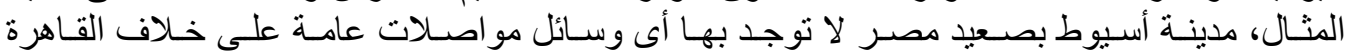

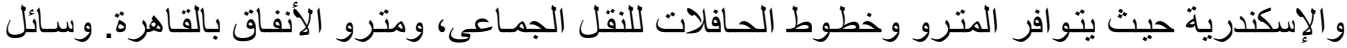

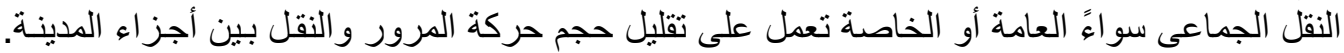

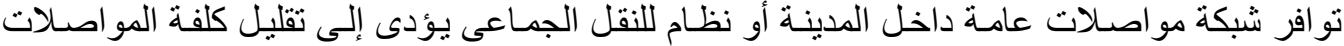

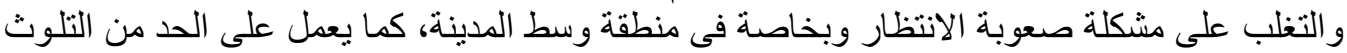
البيئى الناجم من كثافة حركة السيار ات الخاصة.

\section{6-2-2 عدم الإهتمام بمواقف السيارات فى القوانين المنظمة للعمران:}

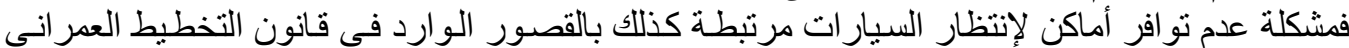

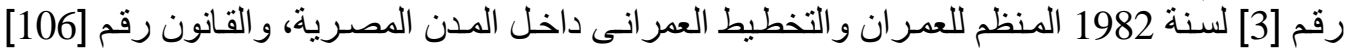

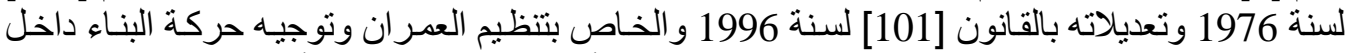

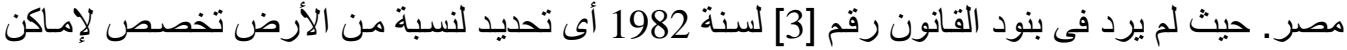

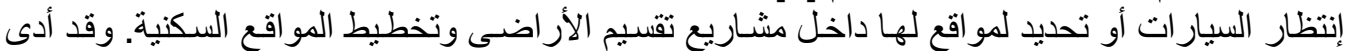

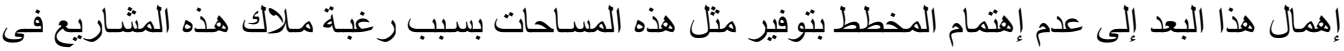

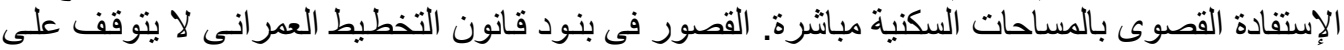

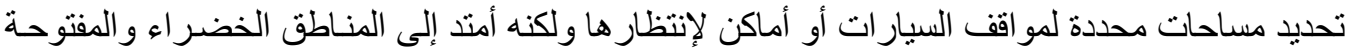

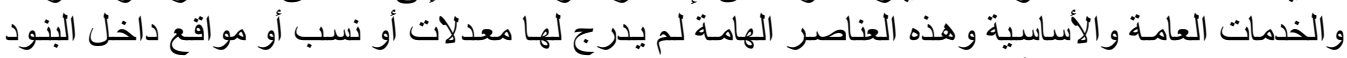
المنظمة لمشاريع التقسيم أو فى المخططات التفصيلية بقانون التخطيط العمر انى. 


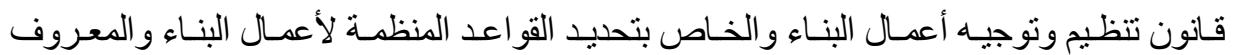

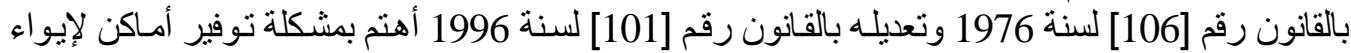

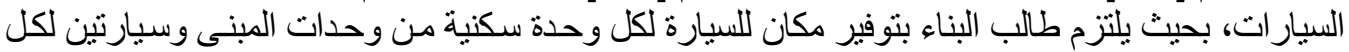

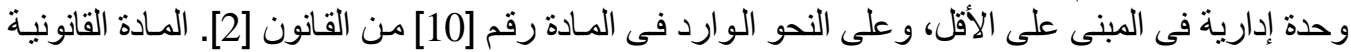

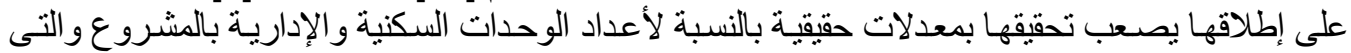

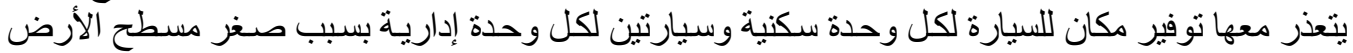
بالنسبة لعدد الوحدات.

7-2 - غياب البعد البيئى فى مواقف السيارات بالثوارع: إلثوار:

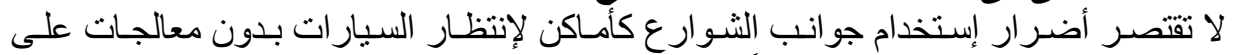

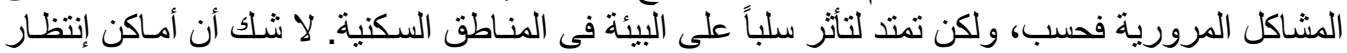

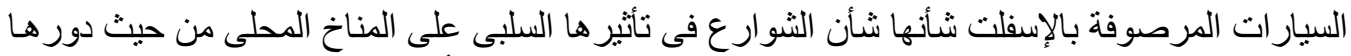

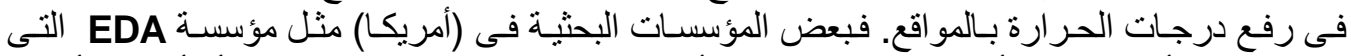

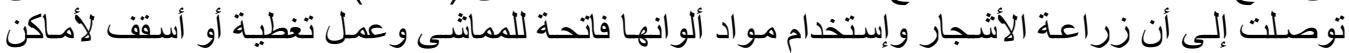

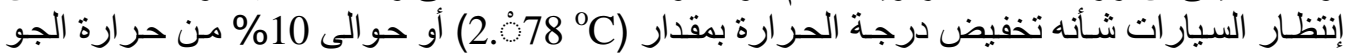

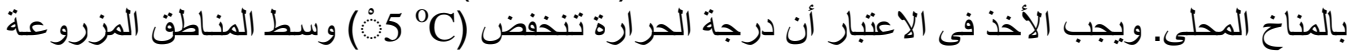

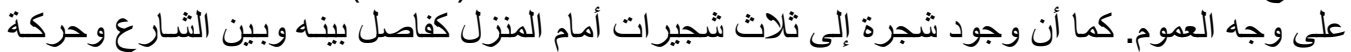

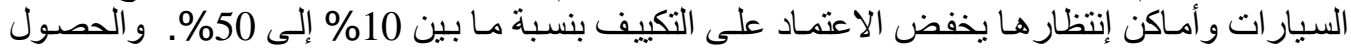

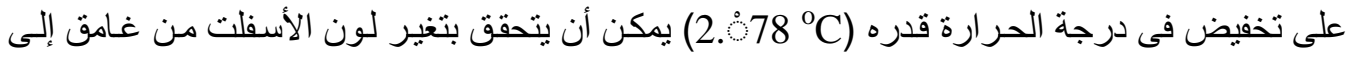

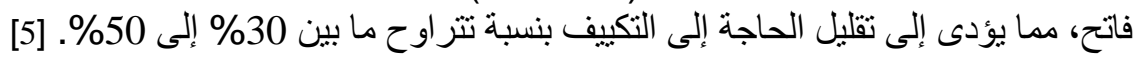

\section{3- الحلول المتبعة حالياً لحل مشكلة إنتظار السيارات داخل الأحياء

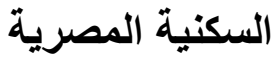

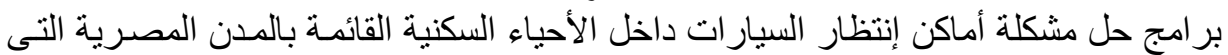

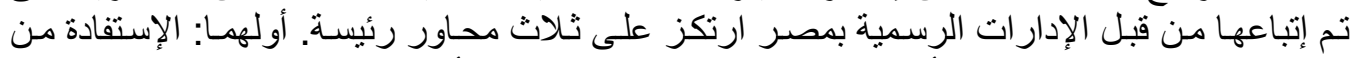

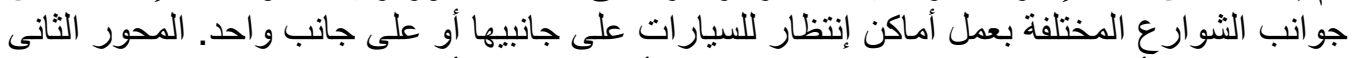

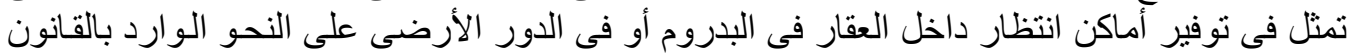

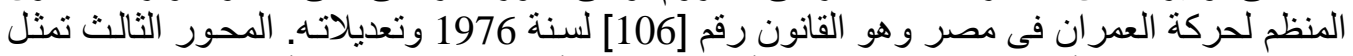

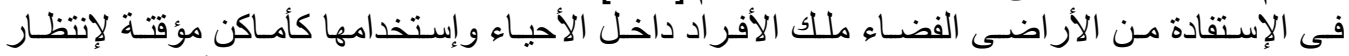

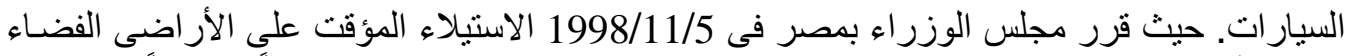

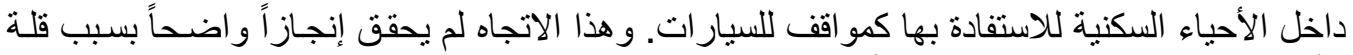

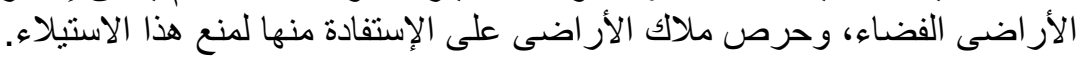

1-3 إنتظار السيارات وعلاقتها بتدرجات الثوارع:

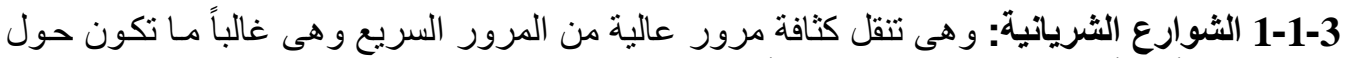

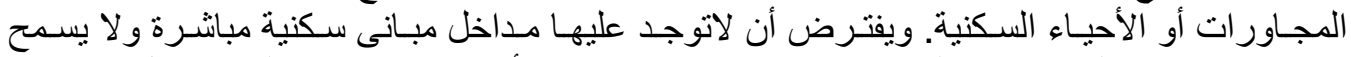

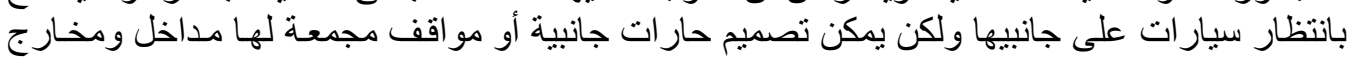
آنـة.

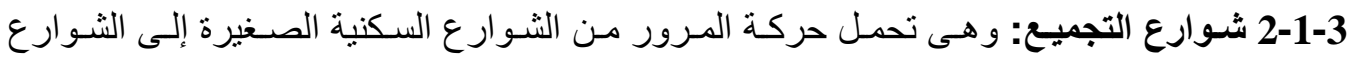

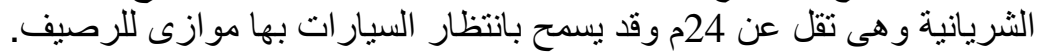




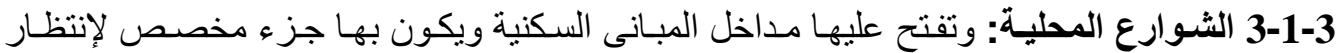

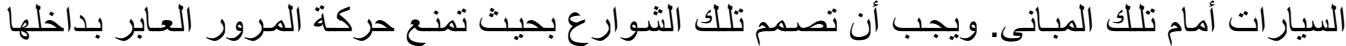

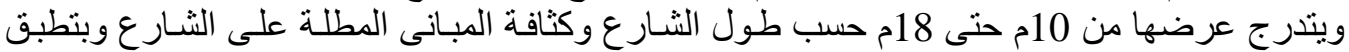
إمكانية توفير مو اقف للسيارات بجوار الأرئ الأرصفة أمام المبانى السكنية.

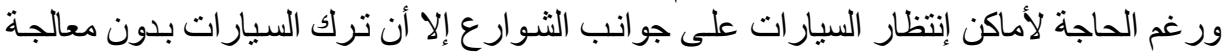

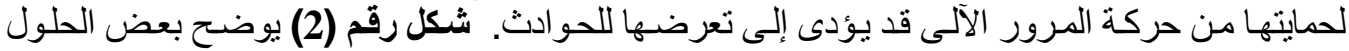
ل الإنظظار السيارات بجوار الرصيف.

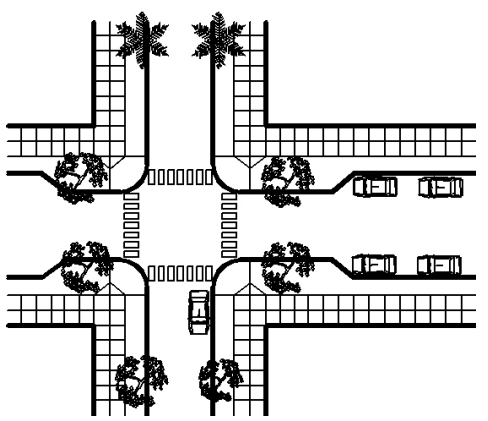

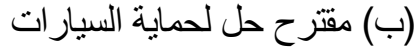
الو اقفة من حركة المرور الآلى

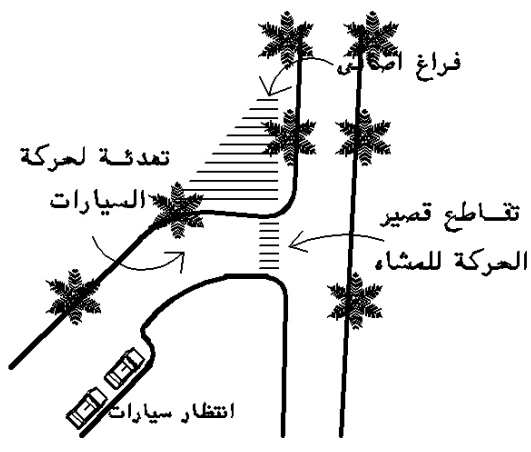

( د ) مقترحة حل لحماية المشاة و السيار ات

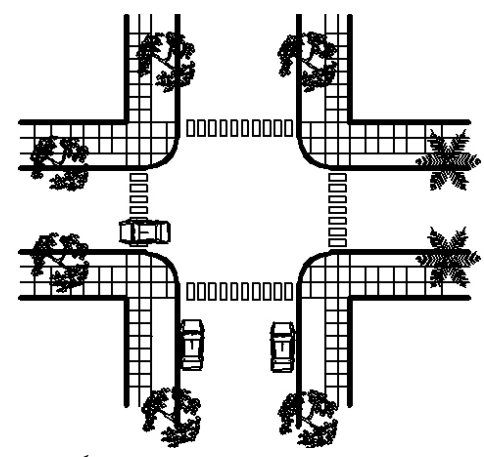

( أ ) وضع غبر مفضل متبع حالياً في التظار السيار ات بجوار الرصيف منفع

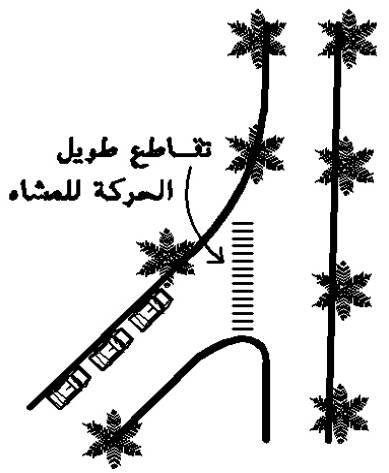

(ج) حل غير مفضل بسبب خطورة للمشاة وللسيار ات الو اقفة دفي

$$
\begin{aligned}
& \text { شكل رقم (2): أوضاع غير مفضلة لانتظار السيار ات على جانب الرصيف }
\end{aligned}
$$

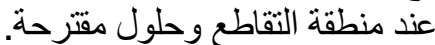

$$
\begin{aligned}
& \text { 2-3-3 إيواء السيارات فى بدرومات العقارات: }
\end{aligned}
$$

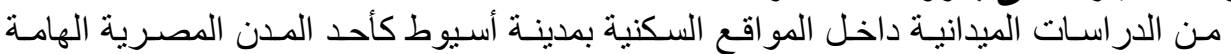

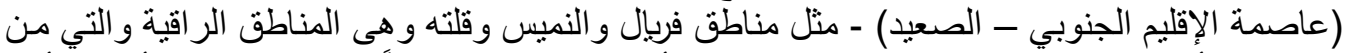

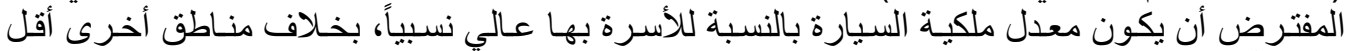

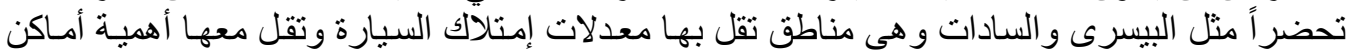

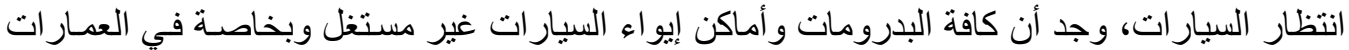

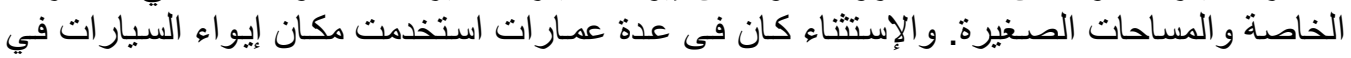




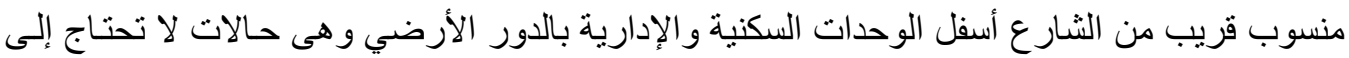

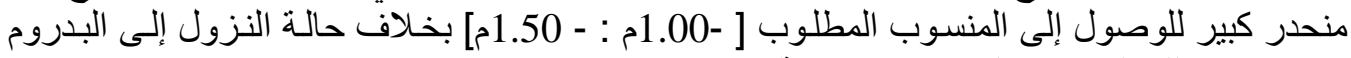
كما يوضح ذلك الكروكى المرفق بالشكل رقم المنول

$$
\text { (ب) مقترح حل }
$$

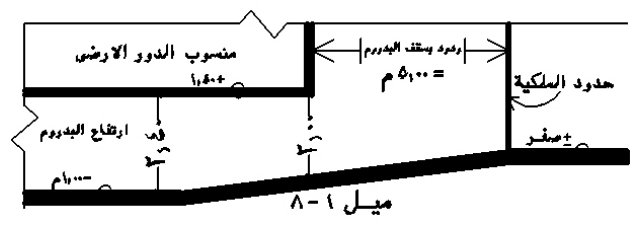

( أ ) حل غبر مفضل

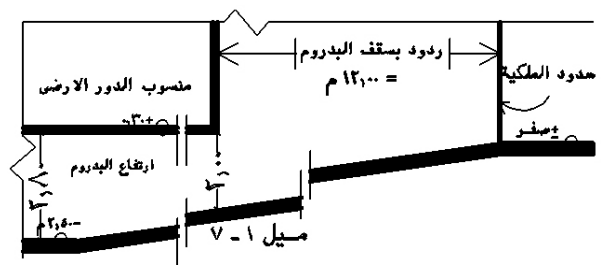

شكل رقم (3): تقليل طول الإنحدار لنزول وصعود السيار ات إلى بدرومات العقار ات بساهم فى الإستفادة من البدروم كموقف سيار ات.

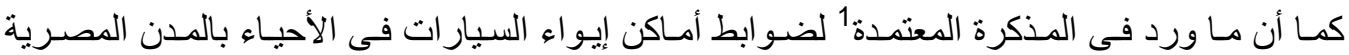

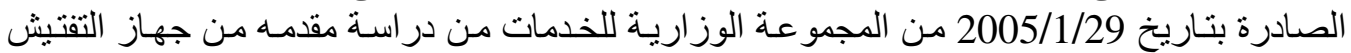

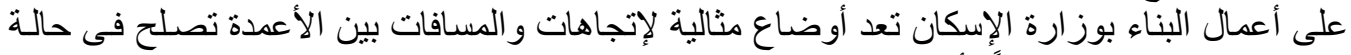

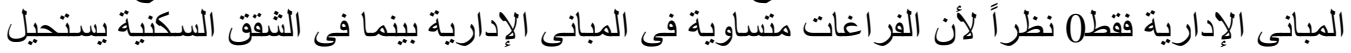
معها هذه الأوضاع المنالية.

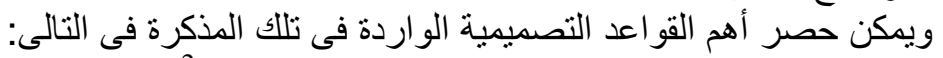

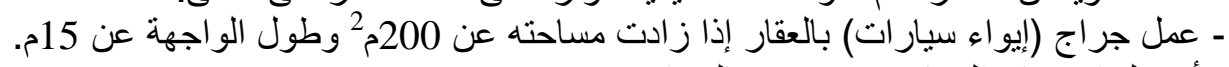

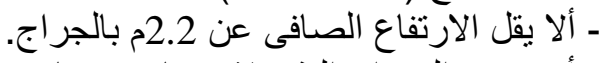

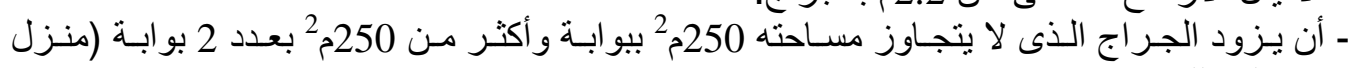

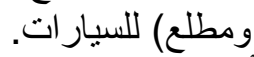

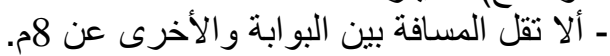

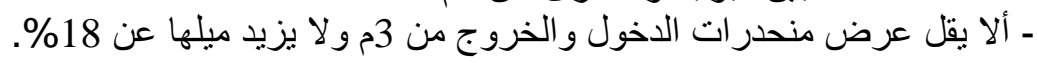

1-2-3 مثاكل إيواء السيارات فى بلرومات العمارات: ويمكن رصد أهم المشاكل والأضرار المباثشرة

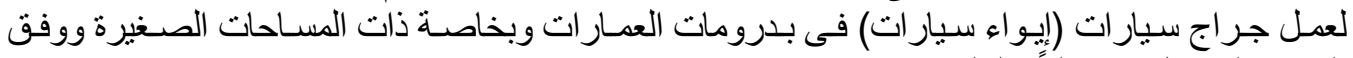

القو اعد المعمول بها حالياً كالتالى: [4اءل)

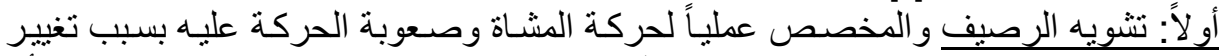

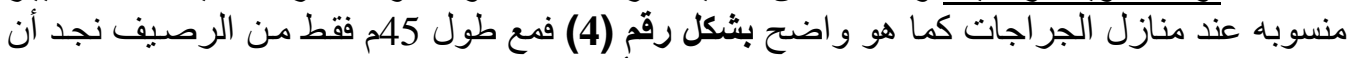

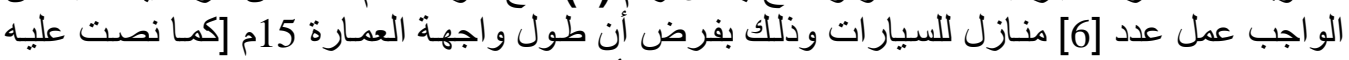

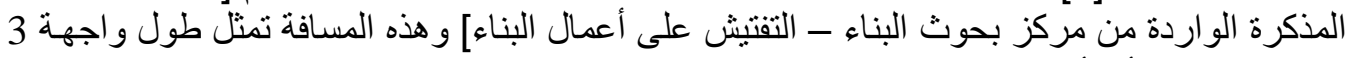

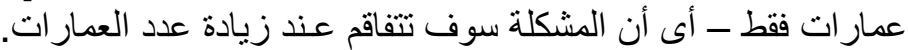

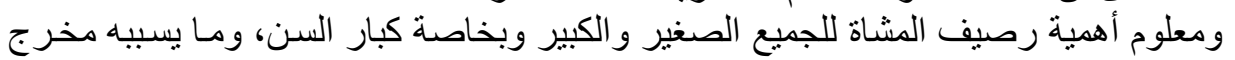
السيار ات من قطع لاستمر ارية الرصيف مما يؤدى إلى صعوبة الحركة عليه.

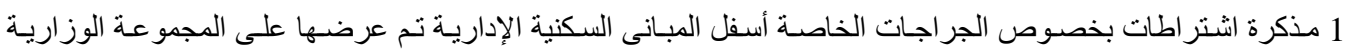

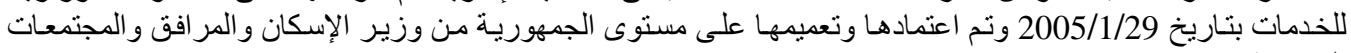
العمر انية برقم 7033 بتاريخ 2005/7/19. 

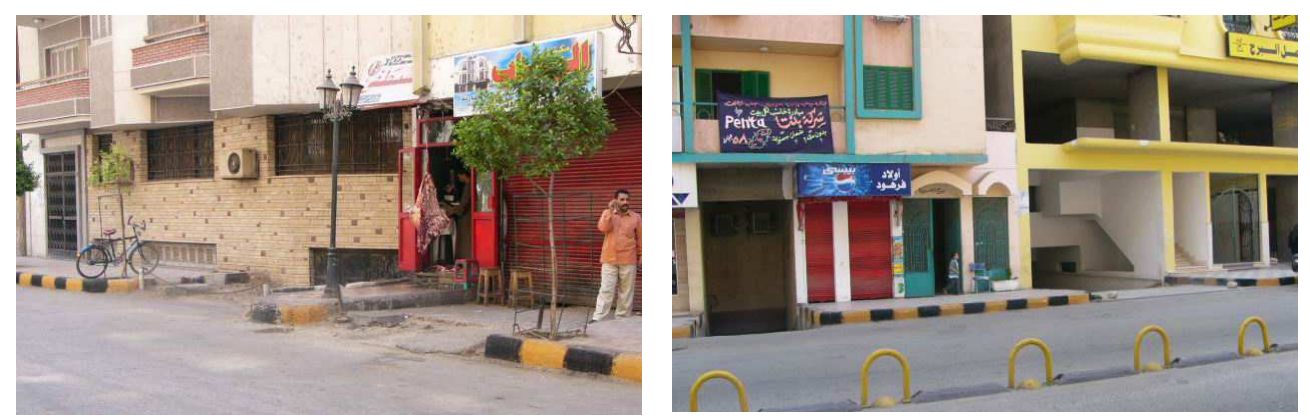

[ أ ] و اجهة عقار ات بها منازل للسيار ات حسب القو اعد المعمول بها وما يسببه ذلك من خطورة فى وفي النزول و الصعود وضياع قيمة الرصيف التصول

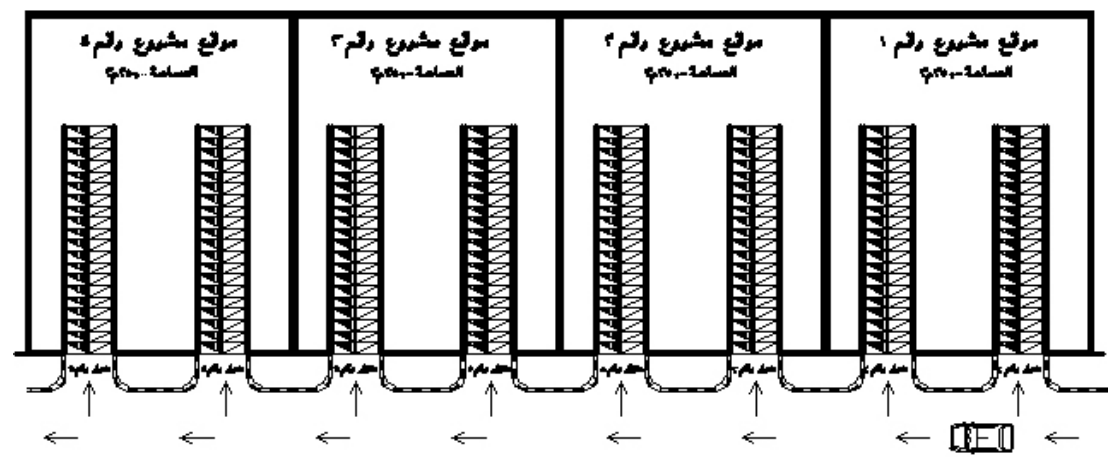

المسقط

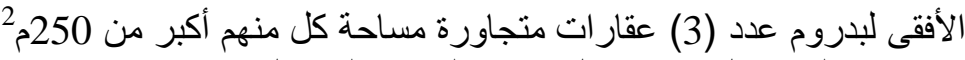

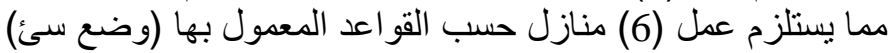

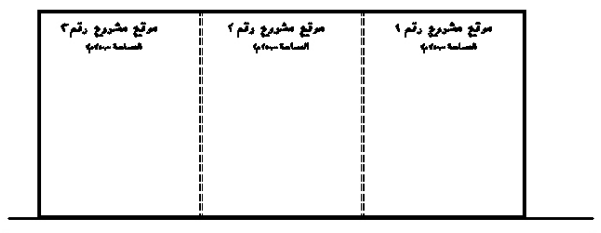

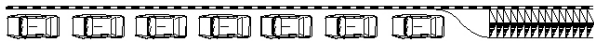

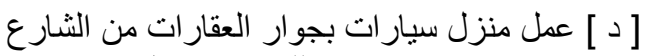

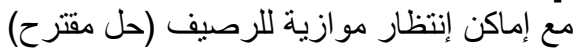

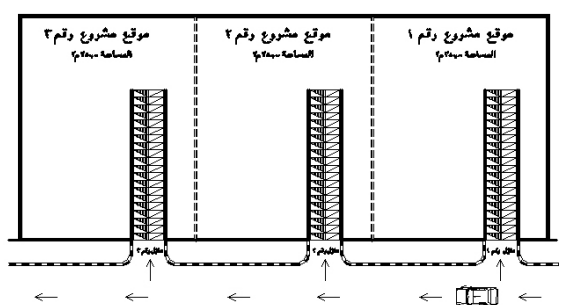

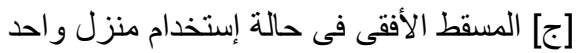

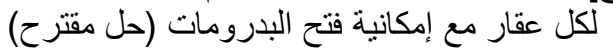

\section{شكل رقم (4): حل مقترح لمشكلة تعدد منازل السيار ات فى العقار ات المتجاورة.}

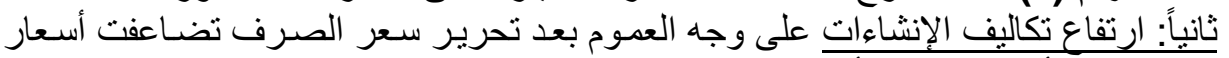

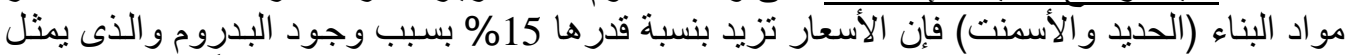

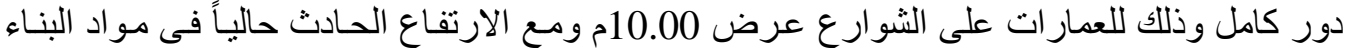

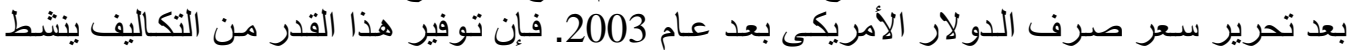

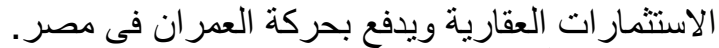

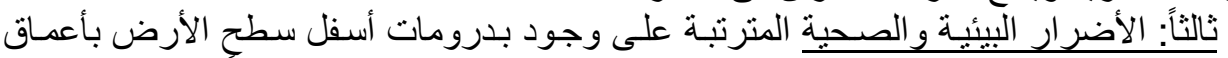

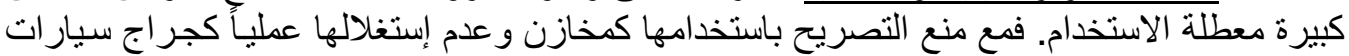


أصبحت هذه البدرومات مناطق للتلوث البيئى. فارتفاع منسوب المياه الجوفية فى البدرومات مـع عدم

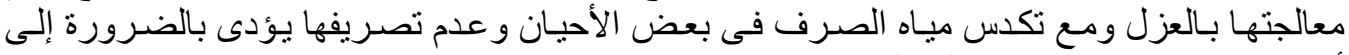
أضر ار بيئية وصحية كبيرة بلى على السكان.

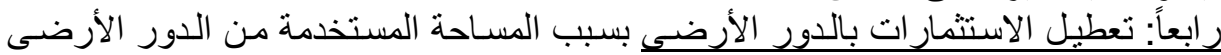

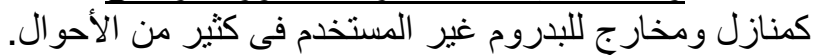

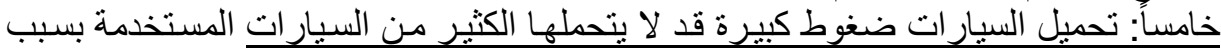

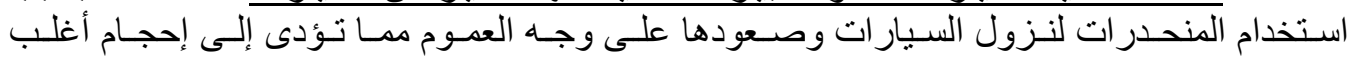
المستخدمين عن الإستفادة بالجراجة التجات.

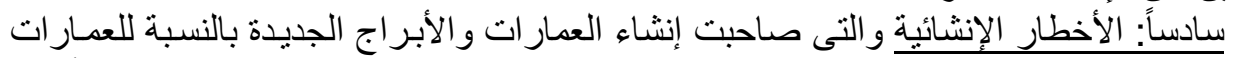

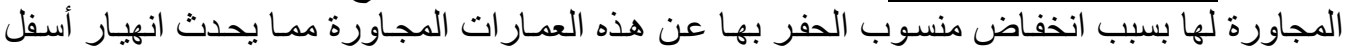

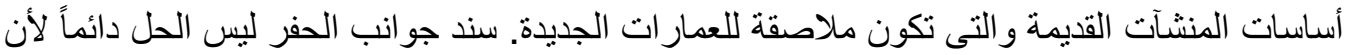

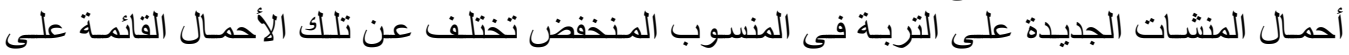

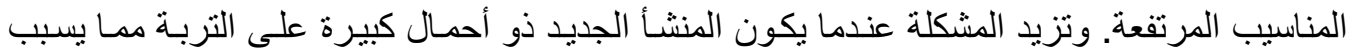

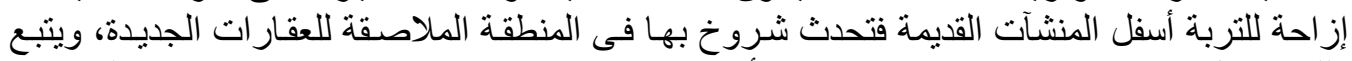

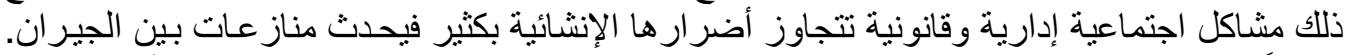

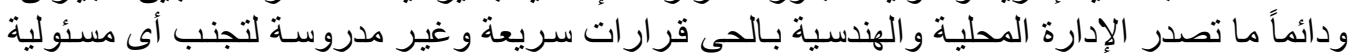

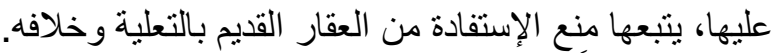

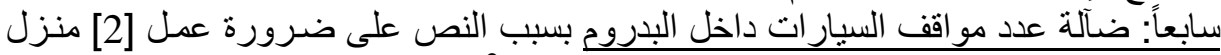

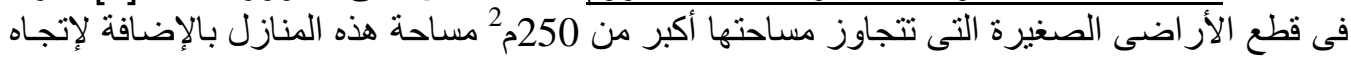

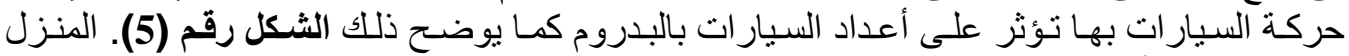

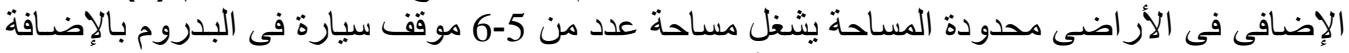
لتشوية الرصيف وضياع الإر مساحة من الدور الأرضى.

\section{4- أهم المقترحات التخطيطية والتصميمية لحل مشكلة أماكن إنتظار السيارات داخل الأحياء السكنية:}

1-4 أهمية توفر وسائل النقل الجماعى:

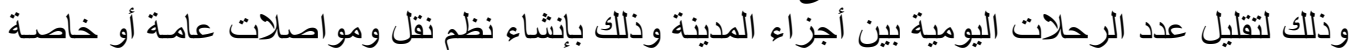

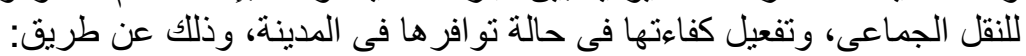

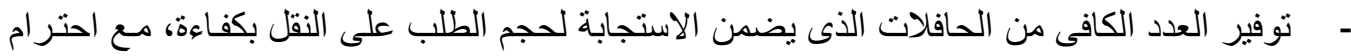

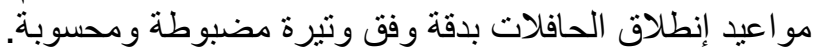

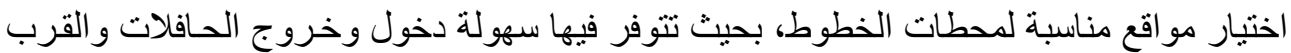
من الأسواق ومر اكز العمل، لتمكين المستعملين من الوصول إليها بأقلّ وقت وجهر مدكنين. 


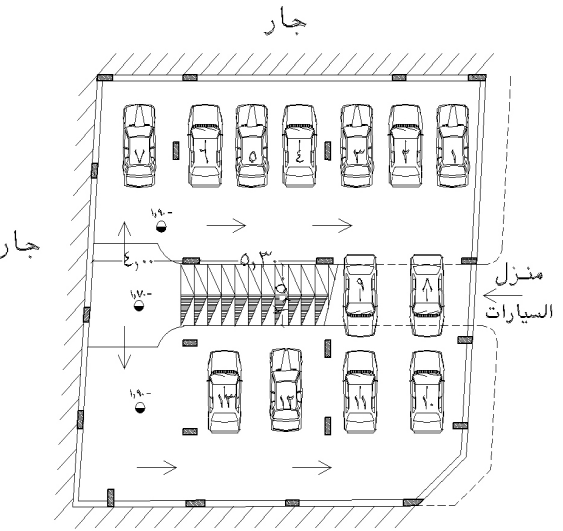

[ب] المسقط الأفقى لنفس البدروم به منزل واحد يوفر موقق لعدد (13) سيارة

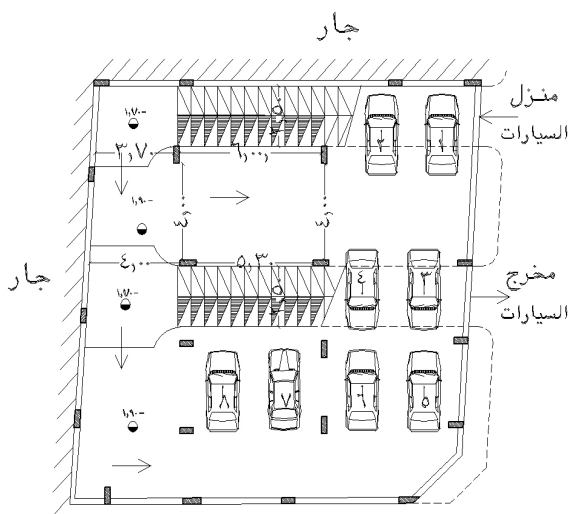

[ [ ] [المسقط الأفقى لبدروم عقار مساحته 300م منزل ومطلع بوفر موقف لعدد (8) سيار الات منات

شكل رقم (5): مساقط العقار ات توضح زيادة أعداد مو اقف السيارات بالبدروم فى حالة وجود منزل

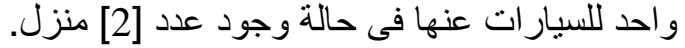

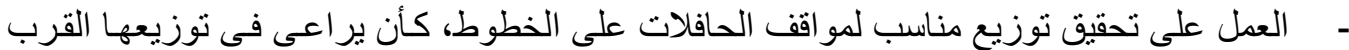

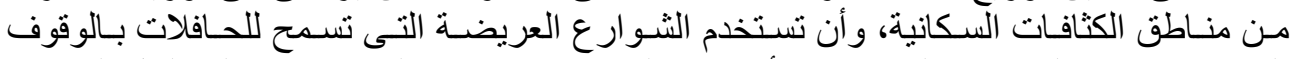

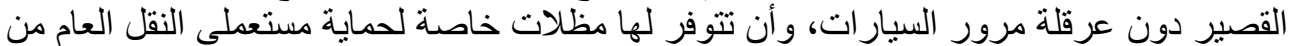
الأمطار و أثنعة الثمس أثناء انتظار الخدمة.

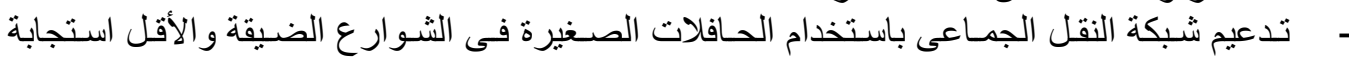

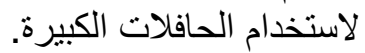

\section{2-4 الإستفادة من المناطق المفتوحة بالمواقع السكنية:}

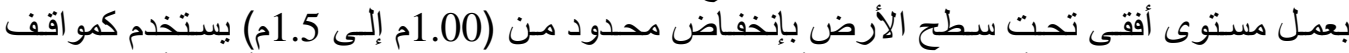

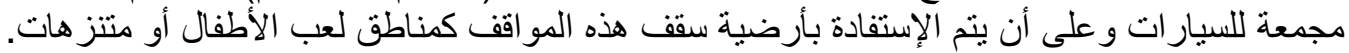

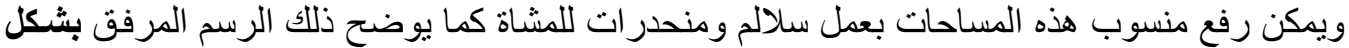

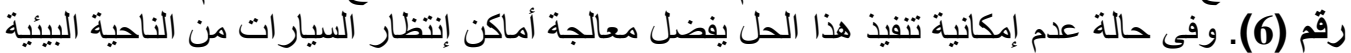

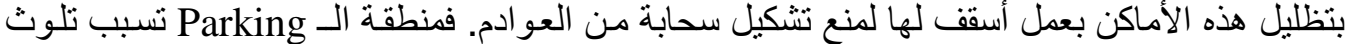

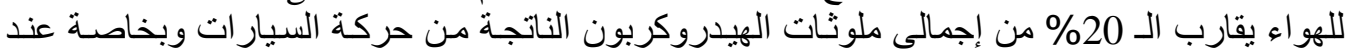

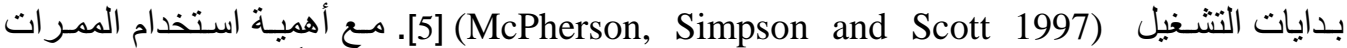
الصناعية مثل الخرسانة المعالجة لتحمل حركة السبار ات والتبليطات الزلطية بدلاً من الأسفلت.

\section{3-4 عمل جراجات مجمعة فى مبانى متعددة الأدوار:}

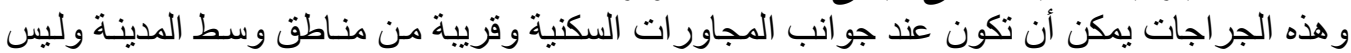

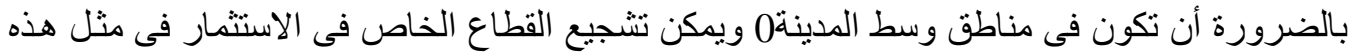
المشاريع، بوضع آلية للحو افز من إعفاءات ضرينية ونية ونظم تمويل ميسرة. 


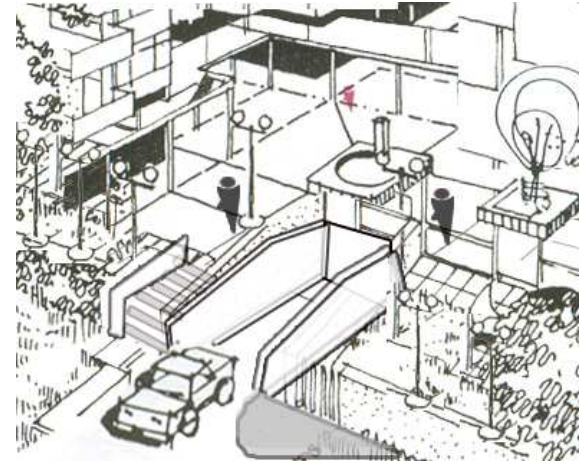

مو اقف سيار ات تعلوها حدائق أو ملاعب أطفال

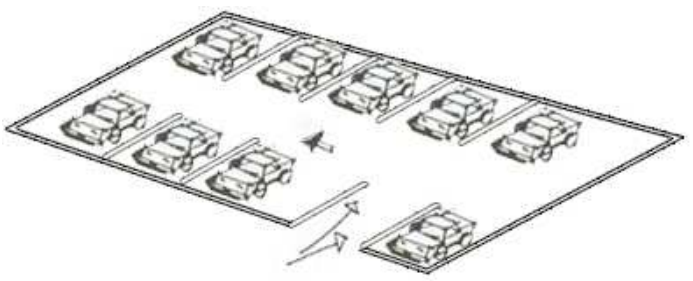

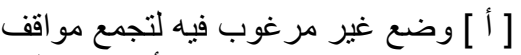

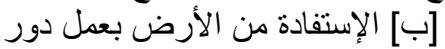
إنتظار السيار ات لا يحقق الإستفادة الكاملة من الأرض بعل درض

شكل رقم (6): أهمية الإستفادة من الأرض بعمل جر اجات متعددة الأدوار أو جر اج يعلوه مناطق مفتوحة.

\section{4-4 معالجة القصور الحادث في قانون التخطيط العمراني:}

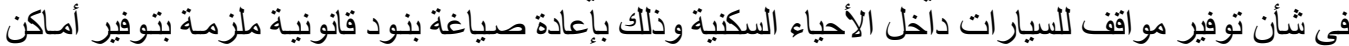

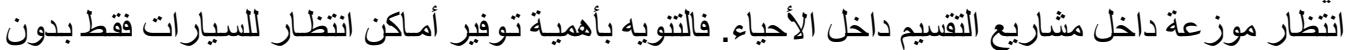

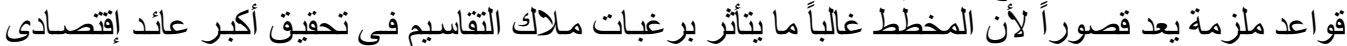

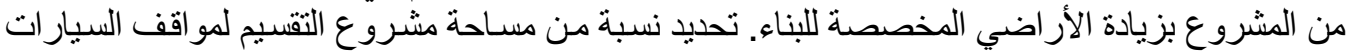
يعتبر من أنسب الحلول التي يجب أن ينص عليها القو انين المنظمـة لمشرو عات التقبيم. أهمية محاكاة البنود

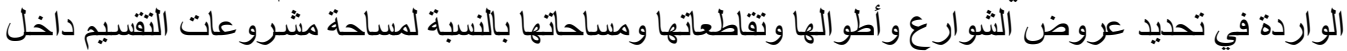
الأحياء السكنية على النحو الوارد في الجدول رقم (2) كمقترح لصياغة محددات تصميمية تصـاغ في بنود

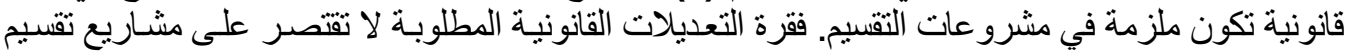

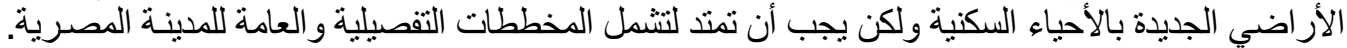

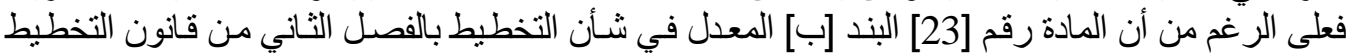

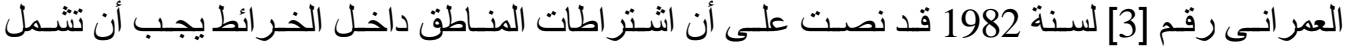
اثتر اطات أماكن التحميل والتفريغ خارج حدود الثار ع (داخل الملكيات الخاصة) و غير ها، الإ أن عدم تحديد أهم هذه الثروط أو القو اعد الواجب الالتزام بها أفرغت المادة القانونية من هدفها ومضمونها.

\section{5-4 أهمية رفع منسوب أرضية البدروم بالقدر المناسب:}

بالنسبة لمنسوب الثارع لتقليل هبوط السيار ات في المنحدرات لأقل حد ممكن. فعلى سبيل المثنال لكل

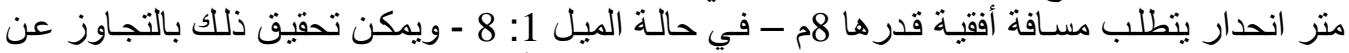

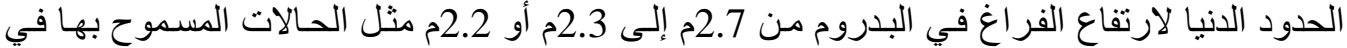

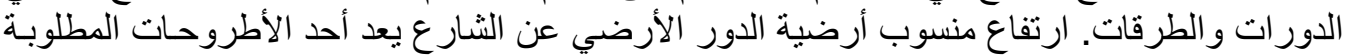

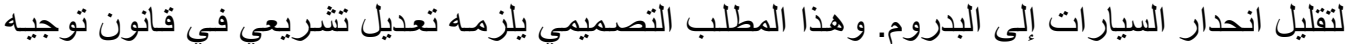

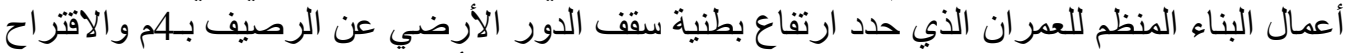

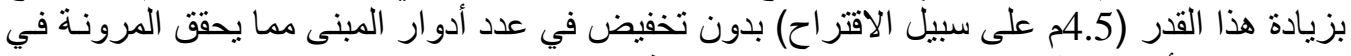

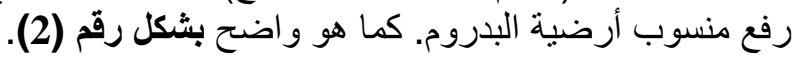


جدول رقم (2): مقترح لصياغة بنود قانونية محددة لتوفير أماكن أنتظار السيار ات بالمحاكاة بالبنود القانونية الخاصة بالشوار ع فى القانون رقم [3] لسنة 1982 بشأن التخطيط العمر انى.

\begin{tabular}{|c|c|}
\hline القانونية لحلة مقترحة لمعلة عدالجة القصور في افر أماكن أنتظارد & 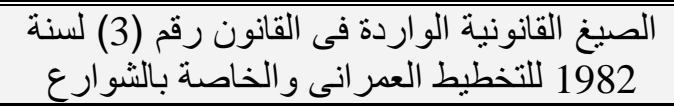 \\
\hline 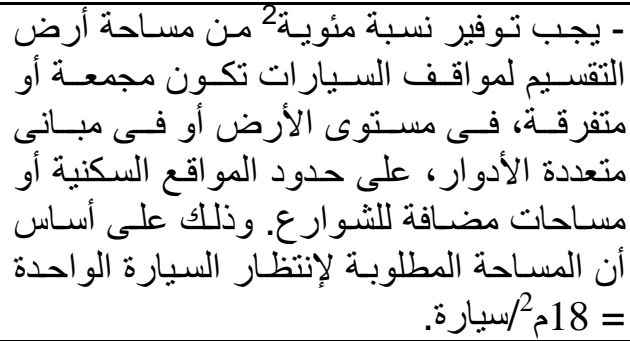 & 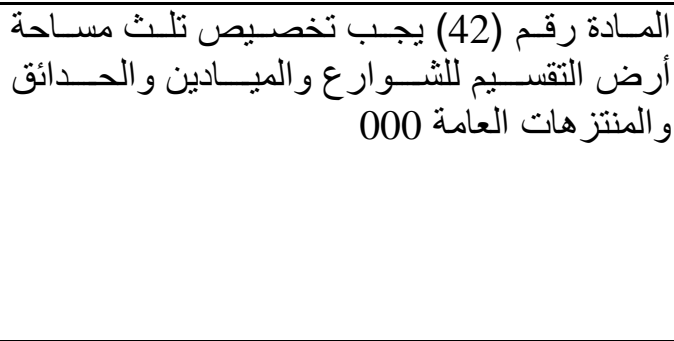 \\
\hline 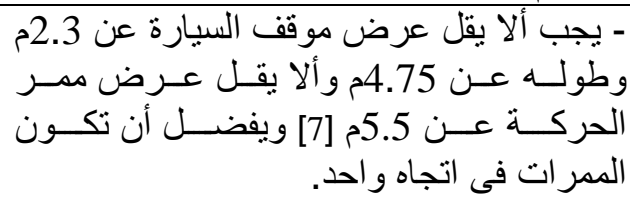 & 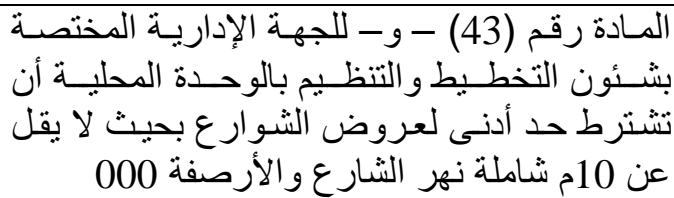 \\
\hline 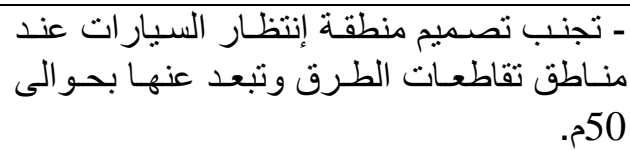 & 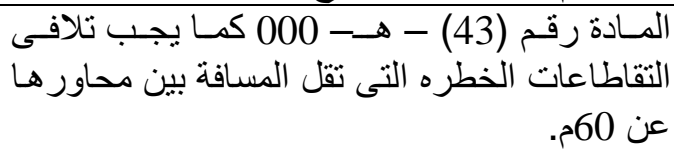 \\
\hline ـ ـ تجنب الرية. إنتظلار فى منـاطق المنحنيـات الأفقيـة & 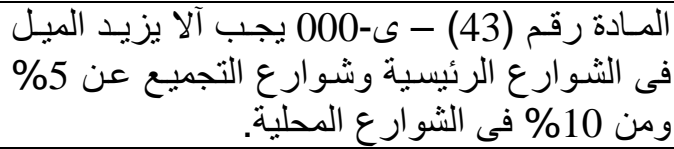 \\
\hline
\end{tabular}

\section{6-4 لحل مشكلة الإختلافات فى منسوب الرصيف بالشارع:}

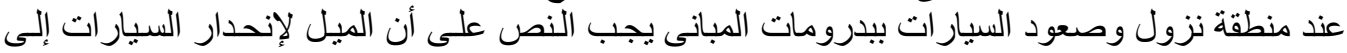

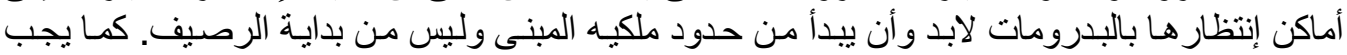

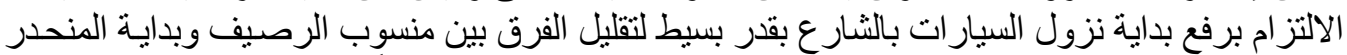

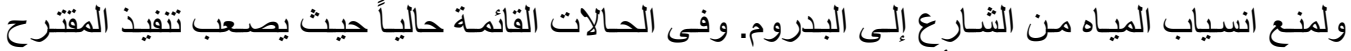
السابق، فيجب عمل درجة سلم أو الثتين لإمكانية النزول الفي من الرصيف إلى منسوب بداية الإنحدار جهة

4-4 تقليل عدد منازل السيارات في البلرومات:

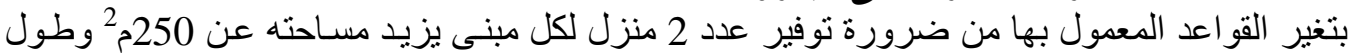

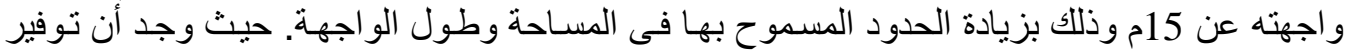

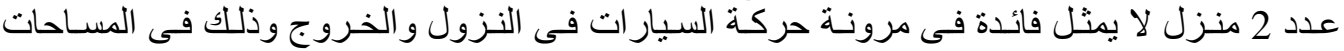

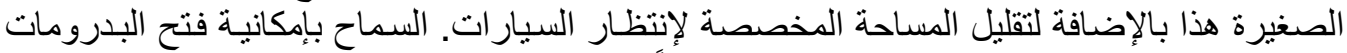

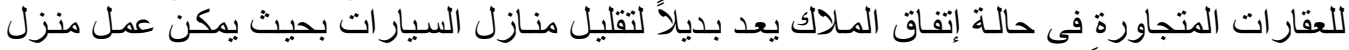

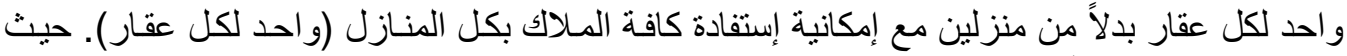

يوضح ذللك الثكل رقم (4).

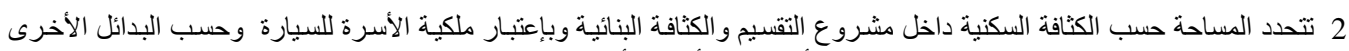
لمو اقق السيار ات داخل المواقع السكنى سواء بالبدروم أو الدور الأرضى أو فى الفر اغات المتروكة من الموقع. 


\section{8-4 تحديد أماكن الإنتظار فى الثوارع حسب كثافة المرور بها:}

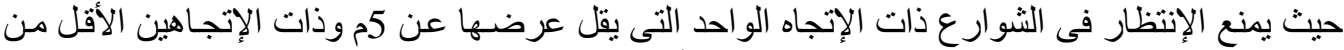

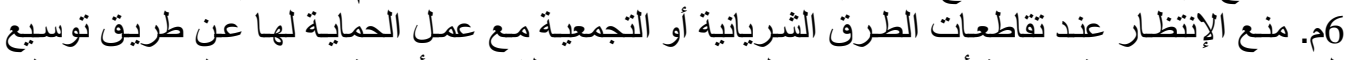

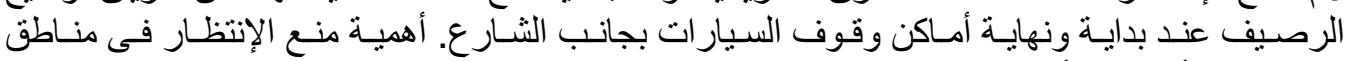

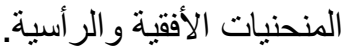

\section{9-4 تحديد إتجاهات الحركة فى الثوارع المحلية:}

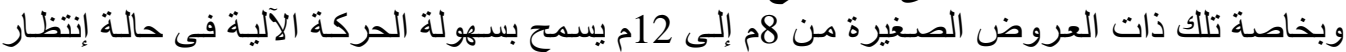
السيار ات على جانبى الثنارع و على أن يكون الإنتظار موازى للإصنيف.

\section{5- الخلاصة والتوصيات}

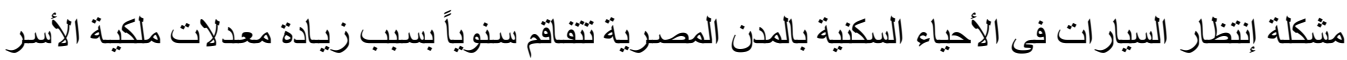

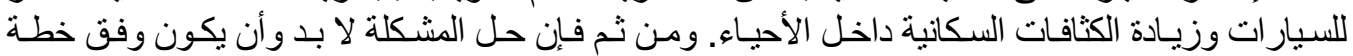
و اضحة وشاملة. ويمكن تحديد أهم محاور هذه الخطة فى التوصيات التالتالية:

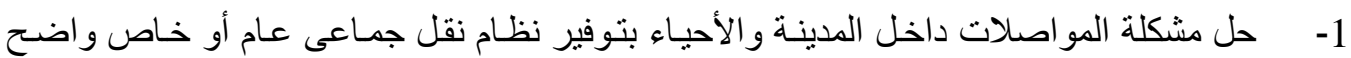
يسمح بتقليل إستخدام السبار ات التات الخاصة. 2- تحجيم الإسكان العشو ائى والإسكان غير الملتزم بقوانين الارتفاع داخل الأحياء السكنية القائمـة

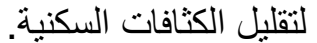

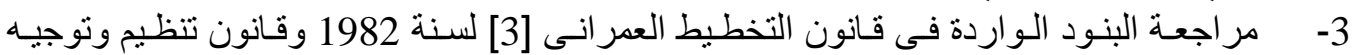

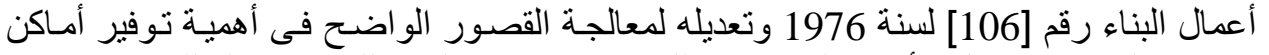

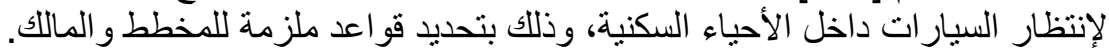

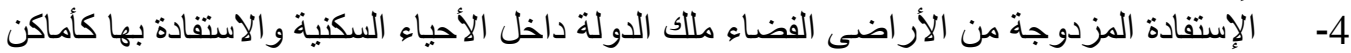

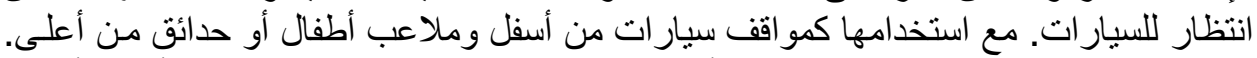

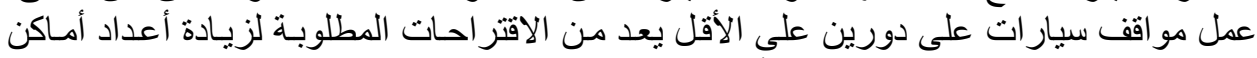
إنتظار السيارات داخل و على حدود الأحباء السكنية.

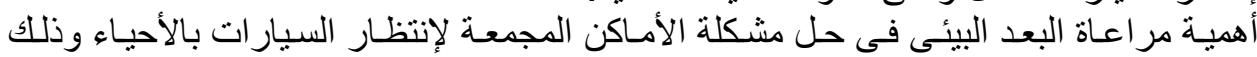

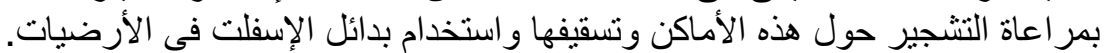

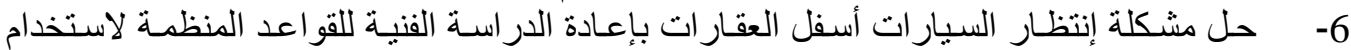
البدروم كجر اج لتحقيق أنسب الحلول ألهار لها.

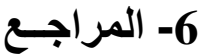

القانون رقم [3] لسنة 1982 بإصدار قانون التخطيط العمر انى الإنى

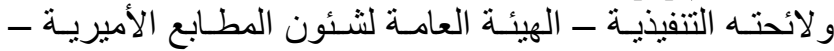

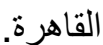

القانون رقم [106] لسنة 1976 في شـأن توجيه وتنظيم أعمال

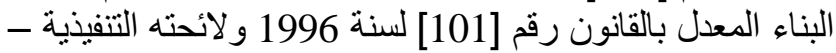
الهيئة العامة لنئون المطابع الأميرية ــ القاهرة. 


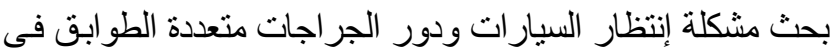

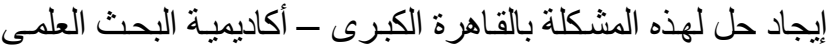

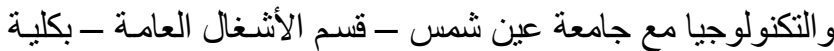

الهندسة ـ التقرير النهائى - نوفمبر 1993 - القاهرة.

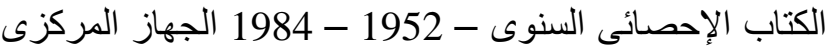

للتعبئة العامة و الإحصاء - ليونيو 1985 - القاهرة.

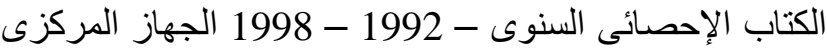

للتعبئة العامة و الإحصاء - يونيو 1999 - القاهرة.

1997 - أسيوط في عيدها - مركز المعلومـات ودعم اتخـاذ القرار - محافظة أسيوط .

دكتور/ 2003 - التصميم و التخطيط الهندسى للطرق الحضرية و الخلوية ـ دار الراتب الجامعية - بيروت ـ لبنان.

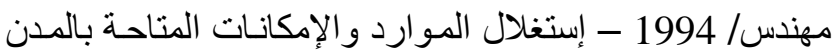

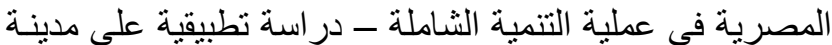

أسيوط - بحث غير منشور - رسالة ماجستير - كليـة الهندسـة

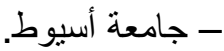

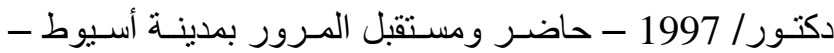

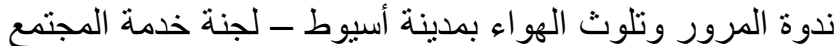

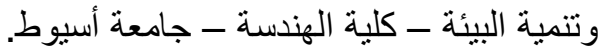

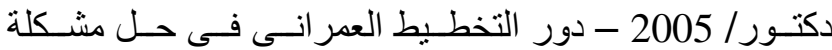

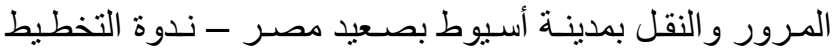

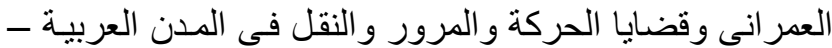

حماة - سوريا

] [10] محروس ، عصام الدين كمال

\&

[7] [أبو أحمد ، خليل أحمد

] [8] [الليثى ، خالد محمد

[9] [9 ع بس ، محمد أحمد

دكتور / 2000 - جغر افيـة المـدن (الإطـار النظـرى وتطبيقـات

عربية) - مطبعة القوصية شبين الكوم - المنوفية

همام ، أحمد عطية

[11] مصيلحى ، فتحى محمد

[12] Childs, Mark c. Parking Spaces (1999) "A design, implementation, and use manual for architects, planners, and engineers." Mc Graw, New York, USA. 